\title{
Faktor-Faktor yang Berhubungan dengan Penggunaan Metode Kontrasepsi Tradisional
}

\author{
Urip Tri Wijayanti ${ }^{1}$ \\ ${ }^{1}$ Badan Kependudukan dan Keluarga Berencana Nasional Provinsi Jawa Tengah
}

\section{ABSTRACT}

Background: The use of modern contraceptives in Central Java tends to decrease while traditional methods are increasing. The purpose of this study was to determine the factors associated with the use of traditional contraceptives among currently married women aged 15-49 in Central Java Province. The factors discussed include the number of children born alive, wife's age, wife's education, wife's occupation, residence, and access/utilization of family planning information sources.

Method: The research design was cross-sectional, used secondary data from the Central Java SKAP 2019. The total number of respondents was 2.088 married women aged 15-49 years and not currently pregnant. Data collected by interview using a structured questionnaire. Data analysis with univariate analysis and bivariate analysis using the chi-square statistical test with a significance level of $5 \%$.

Results: The research found that most respondents were $\geq 35$ years old, having $\geq$ 2 children, having high education level (senior high school to higher education), not working, living in the cities, and able to use some media to find information about family planning. The related factors to the use of traditional contraceptive methods were education and residences. The number of live birth children, ages, jobs, and the use of media did not influence the use of the traditional contraceptive method.
Correspondence

haidar1602@yahoo.co.id

Article History

Received 1 October 2020

Revised 23 December 2020

Accepted 5 January 2021

Available Online 6 January 2021

\author{
Keywords \\ Maternal health \\ Contraception \\ Contraceptive method \\ Traditional contraception
}

DOI

10.14710/jpki.16.1.14-22

\section{PENDAHULUAN}

Provinsi Jawa Tengah merupakan provinsi dengan jumlah penduduk terbanyak ke tiga setelah Jawa Barat dan Jawa Timur. Menurut data BPS tahun 2019 penduduk provinsi Jawa Tengah sebesar 34.718.204 jiwa, dengan perincian laki-laki sejumlah 17.212.455 jiwa dan wanita 17.505.749 jiwa. Jumlah tersebut mengalami pertumbuhan sebesar $0,66 \%$ dibandingkan pada tahun 2018. Persentase pertumbuhan itu akan terus meningkat jika tidak segera diatasi. Peningkatan akan membawa konsekuensi ledakan bayi dan masalah-masalah sosial lainnya, bila kebutuhan terhadap informasi dan pelayanan Keluarga Berencana/KB tidak terpenuhi ${ }^{1}$.

Upaya yang telah dilakukan pemerintah dalam memenuhi pelayanan keluarga berencana diantaranya adalah dengan menggalakkan pemberian pelayanan yang berkualitas melalui peningkatan akses dan kualitas informasi serta konseling dan pelayanan keluarga berencana ${ }^{2}$. Langkah ini juga merupakan salah satu strategi dalam mewujudkan tujuan Sustainable Development Goals (SDGs) 2030 nomor tiga yakni menjamin kehidupan yang sehat dan mendorong kesejahteraan bagi semua orang di segala usia.

Keluarga Berencana (KB) diartikan sebagai suatu program yang dimaksudkan untuk membantu para pasangan dan perorangan dalam mencapai kesehatan reproduksi, mencegah kehamilan yang tidak diinginkan dan mengurangi insiden kehamilan berisiko tinggi, kesakitan dan kematian. Selain itu KB juga bertujuan untuk membuat pelayanan yang bermutu, terjangkau, diterima dan mudah diperoleh bagi semua orang yang membutuhkan, meningkatkan mutu, komunikasi, informasi, dan edukasi, konseling dan pelayanan, meningkatkan partisipasi dan tanggung jawab pria dalam praktek $\mathrm{KB}$, dan meningkatkan pemberian Air Susu Ibu (ASI) untuk penjarangan kehamilan ${ }^{3}$. Hal ini berarti para peserta $\mathrm{KB} /$ pengguna alat kontrasepsi wajib mendapatkan informasi lengkap mengenai berbagai alat kontrasepsi, kelebihan dan kekurangannya serta kesesuaian dengan kondisi kesehatan sehingga dapat menentukan alat kontrsepsi yang dikehendaki. Ada berbagai pilihan alat/cara KB yang tersedia, pertama alat/cara KB modern meliputi tubektomi, vasektomi, implant, IUD, 
pil, kontrasepsi darurat, kondom pria, kondom wanita, dan intravag. Selain itu, ada pula alat / cara KB tradisional. Metode tersebut antara lain coitus interruptus / senggama terputus, metode kalender atau pantang berkala dan metode hari standar atau penggunaan gelang manik siklus.

Pemilihan metode kontrasepsi yang tepat dan kepatuhan dalam penggunaan metode kontrasepsi merupakan langkah untuk menghindari kehamilan. Kasus-kasus kegagalan yang terjadi dikarenakan ketidakpatuhannya akseptor KB dalam menggunakan kontrasepsi. Bahkan kegagalan kontrasepsi merupakan penyebab utama kehamilan tidak diinginkan di seluruh dunia $^{4}$. Pembinaan dan pendampingan kepada akseptor KB aktif perlu dilakukan secara intens, agar mereka memiliki keberlanjutan menjadi peserta KB aktif dan membantu memecahkan masalah-masalah yang terjadi melalui konseling KB.

Kontrasepsi tradisional masih menjadi pilihan bagi pasangan usia subur di Jawa Tengah dibandingkan penggunaan kontrasepsi modern. Hal tersebut dapat dilihat dari target tahun 2019 sebesar 63,93\% wanita kawin usia 15-49 tahun menggunakan kontrasepsi modern, namun pencapaiannya hanya sebesar $61,32 \%$. Bahkan pencapaian tersebut menurun sebanyak $1,33 \%$ bila dibandingkan dengan tahun sebelumnya. Trend penggunaan kontrasepsi tradisional justru cenderung meningkat. Hasil SKAP 2017 menunjukkan penggunaan kontrasepsi tradisional sebesar 2,9\% dan naik menjadi 4,8\% di tahun 2018. Hasil SDKI 2012 dan 2017 juga menunjukkan penggunaan kontrasepsi modern cenderung menurun. SDKI 2012 menyebutkan sebesar 60\% Pasangan Usia Subur menggunakan kontrasepsi modern dan angkanya turun menjadi 59,5\% di tahun 2017. Penggunaan kontrasepsi tradisonal justru meningkat dari 3,8\% di tahun 2012 menjadi 6,2\% di tahun 2017. Hasil Susenas 2019 melaporkan persentase penggunaan kontrasepsi tradisional di provinsi Jawa Tengah yang berada di atas angka nasional. Angka nasional untuk penggunaan kontrasepsi tradisional adalah 1,8\%, sementara Jawa Tengah mencapai 2,02\%. Hal ini menunjukkan masih banyak wanita usia subur di Jawa Tengah yang memilih menggunakan metode kontrasepsi tradisional dibandingkan modern ${ }^{5}$.

Penelitian sebelumnya tentang faktor yang berhubungan dengan penggunaan kontrasepsi dilakukan menunjukkan hasil tidak terdapat hubungan yang bermakna antara penghasilan keluarga, ketersediaan layanan $\mathrm{KB}$, ketersediaan informasi $\mathrm{KB}$ dan kepemilikan asuransi kesehatan dengan penggunaan kontrasepsi tradisional. Beberapa alasan yang melatarbelakangi para wanita usia subur menggunakan kontrasepsi tradisional antara lain karena faktor suami, yaitu suami tidak mengizinkan atau mendukung istrinya menggunakan kontrasepsi modern ${ }^{5}$. Dalam budaya patriarki di Jawa tengah, suami adalah kepala keluarga yang berhak mengambil keputusan, termasuk di antaranya keputusan jumlah anak, tempat persalinan hingga pemakaian alat kontrasepsi ${ }^{1}$. Efek samping dari penggunan kontrasepsi modern menjadi pertimbangan seseorang menggunakan kontrasepsi tradisional meskipun ketersediaan informasi $\mathrm{KB}$ cukup baik dan akses untuk mendapatkan pelayanan $\mathrm{KB}$ modern sangat terjangkau. Penelitian di Nigeria dan Filipina menyebutkan bahwa ketakutan akan efek samping dari metode kontrasepsi modern mendorong wanita untuk mengandalkan metode tradisional yang kurang efektif ${ }^{7}$. Penelitian lainnya mengatakan bahwa faktor pribadi, faktor ekonomi dan faktor sosial budaya mendukung penggunaan kontrasepsi tradisional ${ }^{8}$. Pemilihan metode kontrasepsi disebabkan oleh beberapa hal termasuk kepercayaan. Kepercayaan memberikan perspektif pada manusia dalam mempersepsi kenyataan, memberikan dasar bagi pengambilan keputusan dan menentukan sikap9 .

Menurut Bertrand, determinan penggunaan kontrasepsi meliputi faktor sosiodemografi, faktor psikososial dan faktor yang berhubungan dengan pelayanan kesehatan. Indikator yang termasuk ke dalam faktor sosiodemografi adalah pendidikan, pendapatan keluarga, status pekerjaan, jenis rumah, status gizi, usia, suku dan agama. Faktor psikososial meliputi sikap dan keyakinan yang merupakan kunci penerimaan keluarga berencana ${ }^{10}$. Faktor yang berhubungan dengan pelayanan kesehatan antara lain pengetahuan tentang sumber kontrasepsi, jarak ke pusat pelayanan dan keterlibatan dengan media massa. Bulatao menyatakan determinan pilihan alat/cara KB terdiri dari empat kelompok, yaitu: 1) penggunaan kontrasepsi yaitu yang bertujuan untuk pengaturan kelahiran (menjarangkan atau membatasi kelahiran), 2) kompetensi berkontrasepsi yaitu kemampuan PUS menggunakan alat/cara KB dengan efektif, 3) evaluasi kontrasepsi yaitu penilaian spesifik terhadap penggunaan alat/cara KB baik secara praktis maupun moral, termasuk pertimbangan efek samping dan kenyamanan pengguna terakhir, dan 4) akses kontrasepsi yaitu ketersediaan alat/cara KB termasuk informasi untuk mendapatkannya ${ }^{11}$. Menurut Lembaga Demografi FEUI kerangka pikir konseptual Bulatao dapat dianalisis sebagai berikut: untuk faktor-faktor tujuan kontrasepsi dapat digunakan jumlah anak dan tujuan fertilitas (fertility intensions), faktor kompetensi kontrasepsi dapat didekati dengan usia istri, lama menikah, pendidikan suami, pendidikan istri dan status bekerja istri. Faktor evaluasi kontrasepsi dapat digunakan faktor budaya dan sifat program $\mathrm{KB}$, faktor akses kontrasepsi didekati dengan ketersediaan program $\mathrm{KB}$, alat/cara $\mathrm{KB}$ yang diinginkan serta kegiatankegiatan program di wilayah tempat tinggal PUS $^{1}$. 
Penelitian ini bertujuan untuk mengetahui faktor yang berhubungan dengan penggunaan kontrasepsi tradisional pada wanita kawin usia 15-49 di Provinsi Jawa Tengah. Faktor yang dibahas meliputi faktor tujuan, kompetensi dan akses. Faktor tujuan dilihat dari jumlah anak lahir hidup. Faktor kompetensi meliputi usia istri, pendidikan istri, pekerjaan istri, tempat tinggal. Faktor akses diantaranya dilihat dari akses/pemanfaatan sumber informasi $\mathrm{KB}$ melalui radio, televisi dan majalah.

\section{METODE}

Jenis penelitian ini adalah kuantitatif dengan desain belah lintang dan menggunakan data sekunder dari SKAP Jawa Tengah tahun 2019. Variabel bebas pada penelitian ini yaitu jumlah anak lahir hidup, usia istri, pendidikan istri, pekerjaan istri, tempat tinggal, akses /pemanfaatan informasi KB. Variabel terikat dalam penelitian ini penggunaan kontrasepsi tradisional. Sampel pada penelitian ini wanita usia subur usia 15-49 tahun responden SKAP 2019 di Jawa Tengah. Pengambilan sampel secara systematic random sampling. Kriteria sampel adalah semua wanita usia subur dengan status menikah berusia 15-49 tahun dan tidak sedang hamil. Status menikah dalam penelitian berarti status responden yang terikat perkawinan pada saat survei, baik tinggal bersama maupun terpisah dengan pasangannya, kawin sah secara hukum, adat dan agama ${ }^{2}$. Berdasarkan hasil seleksi data didapatkan sebanyak 2.088 orang wanita usia subur yang memenuhi kriteria sebagai unit analisis dalam penelitian ini. Analisis data secara univariat dan bivariate menggunakan uji statistik chi square dengan tingkat signifikansi $5 \%$.

\section{HASIL DAN PEMBAHASAN}

Sebanyak 21,6\% responden memiliki lebih dari 2 anak yang masih hidup, artinya jumlah anak telah cukup atau bahkan lebih dari cukup berdasarkan saran pemerintah dalam menciptakan keluarga berencana. Dengan demikian, responden perlu melakukan pencegahan kehamilan dengan menggunakan alat kontrasepsi yang tepat. Secara umum besar responden sudah melakukan program keluarga berencana. Program ini menganjurkan hanya dua anak dalam satu keluarga. Pembatasan jumlah anak dimaksudkan agar orang tua mampu memenuhi kebutuhan anak-anak, mulai dari kasih sayang, pendidikan, ekonomi, perlindungan, sosialisasi dan lainnya.

Tabel 1 menunjukkan $56,2 \%$ responden berusia $\geq$ 35 tahun, artinya responden telah masuk ke dalam risiko tinggi jika terjadi kehamilan pada usianya. Risiko ini bisa membahayakan kesehatan responden maupun bayi yang dikandungnya, sehingga penggunaan kontrasepsi pada usia ini harus dilakukan agar tidak terjadi kehamilan.

Sebagian besar responden berpendidikan rendah $(62,5 \%)$, tinggal di kota $(50,9 \%)$, bekerja $(50 \%)$ dan telah memanfaatkan media infomasi mengenai pelayanan kontrasepsi modern $(54,7 \%)$.

Tabel 1. Karakteristik responden

\begin{tabular}{lrr}
\hline \multicolumn{1}{c}{ Variabel } & J & Jumlah \\
\hline $\begin{array}{lrr}\text { Jumlah anak masih hidup } \\
\leq 2\end{array}$ & 1.638 & 78,4 \\
$>2$ & 450 & 21,6 \\
\hline Usia & 915 & 43,8 \\
$\quad<35$ & 1.173 & 56,2 \\
$\quad \geq 35$ & & \\
\hline Pendidikan & 1.306 & 62,5 \\
$\quad$ Rendah & 782 & 37,5 \\
$\quad$ Tinggi & & \\
\hline Pekerjaan & 1.043 & 50 \\
$\quad$ Bekerja & 1.045 & 50 \\
$\quad$ Tidak bekerja & & \\
\hline Tempat tinggal & 1.062 & 50,9 \\
$\quad$ Perkotaan & 1.026 & 49,1 \\
$\quad$ Perdesaan & & \\
\hline Pemanfaatan media & 1.142 & 54,7 \\
$\quad$ Memanfaatkan & 946 & 45,3 \\
$\quad$ Tidak memanfaatkan & $\mathbf{2 . 0 8 8}$ & $\mathbf{1 0 0 , 0}$ \\
\hline Total & &
\end{tabular}

Berdasarkan tabel 2 dapat diketahui bahwa penggunaan metode kontrasepsi tradisional pada responden yang memiliki anak hidup $\leq 2$ orang sebanyak 55 responden $(2,6 \%)$. Hasil penelitian ini sesuai dengan penelitian di India bahwa penggunaan kontrasepsi tradisional banyak dilakukan oleh keluarga yang memiliki dua anak masih hidup, dan setidaknya satu anak laki-laki yang masih hidup ${ }^{12}$.

Penggunaan metode kontrasepsi tradisional pada responden yang telah memiliki anak bertujuan untuk menunda maupun mengatur jarak kelahiran berikutnya agar tidak terjadi kondisi adanya dua balita dalam 1 periode di suatu keluarga. Pada fase ini metode kontrasepsi yang dianjurkan berupa suntikan, pil, IUD dan implant bukan metode tradisional. Hal tersebut dianjurkan agar setiap keluarga memiliki perencanaan yang matang tentang jumlah anak dan jarak ideal antar anak.

Berdasarkan hasil uji statistik nilai signifikan sebesar 0,795 dengan demikian propabilitas (signifikansi) lebih besar dari $0,05(0,795>0,05)$, maka tidak terdapat hubungan antara jumlah anak masih hidup dengan penggunaan kontrasepsi. Jumlah anak masih hidup tidak menjadi pertimbangan wanita usia subur beserta pasangannya dalam mengambil keputusan menggunakan metode kontrasepsi tradisional. Hasil ini sejalan dengan penelitian Titaley et al bahwa antara jumlah anak lahir hidup dengan penggunaan layanan KB tidak ditemukan adanya suatu hubungan yang signifikan, dimana pengetahuan lebih memegang peranan penting terhadap penggunaan 
kontrasepsi ${ }^{13}$. Sejalan dengan itu penelitian Lontaan menyebutkan bahwa tidak ada hubungan antara paritas dengan pemilihan jenis kontrasepsi ${ }^{14}$. Berbeda dengan penelitian Wijayanti yang membuktikan ada hubungan antara jumlah anak yang dilahirkan dengan penggunaan kontrasepsi ${ }^{15}$. Begitu pula hasil penelitian Hartono yang mendapat hasil bahwa variabel jumlah anak mempengaruhi pemilihan metode KB wanita usia reproduksi di Indonesia ${ }^{16}$. Jumlah anak menjadi penentu dalam menentukan kontrasepsi. Alasannya antara lain adalah untuk membatasi jumlah anak serta menunda maupun mengakhiri kehamilan bagi pasangan yang sudah tidak menginginkan anak lagi ${ }^{16}$. Penelitian Obwoya et al di Sudan Selatan menjelaskan terdapat hubungan yang siginifikan antara jumlah anak lahir hidup dengan penggunaan kontrasepsi ${ }^{20}$. Hasil penelitian Hossain et al, juga menyatakan jumlah anak yang dilahirkan mempunyai hubungan secara siginikansi terhadap penggunaan kontrasepsi ${ }^{21}$.

Usia dalam penelitian ini dikategorikan $\leq 35$ tahun dan $>35$ tahun. Penggolongan ini merujuk pada fase perencanaan kehamilan yang ideal. Usia < 35 tahun merupakan fase hamil, menunda dan menjarangkan kehamilan. BKKBN pada tahun 2011 menjelaskan secara khusus bahwa wanita usia reproduksi yang berusia 20-35 tahun masih memiliki fungsi reproduksi yang baik, sedangkan usia > 35 tahun pada wanita merupakan fase menghentikan kehamilan. Pada semua fase tersebut sangat dianjurkan menggunakan kontrasepsi modern yang lebih efektif menunda kehamilan maupun mengakhiri kehamilan dibandingkan metode tradisional. Berdasarkan distribusi responden menurut usia, sebanyak 1.173 responden $(56,2 \%)$ berusia $>35$ tahun, sedangkan 915 orang ( 43,8\%) berusia $\leq$ 35 tahun. Secara umum wanita berusia $>35$ tahun berada pada posisi sudah tidak mengasuh balita. Pada usia ini, mereka fokus mendidik anak yang sudah masuk usia sekolah ${ }^{5}$.

Penggunaan metode kontrasepsi tradisional lebih banyak digunakan pada wanita berusia > 35 tahun. Hasil ini sesuai dengan penelitian di India yang menyebutkan bahwa wanita usia 35 tahun ke atas memiliki rasio tinggi untuk menggunakan metode tradisional ${ }^{12}$. Hasil penelitian ini sangat menarik dikarenakan wanita usia subur berusia $>35$ tahun menurut fase perencanaan kehamilan berada pada fase tidak hamil lagi/mengakhiri kehamilan, sehingga diwajibkan menggunkan kontrasepsi modern seperti tubektomi, vasektomi, IUD dan implant. Penggunaan metode tradisional untuk kontrasepsi berpotensi besar terjadi kehamilan. Selain itu, kesehatan wanita usia di atas 35 tahun yang hamil berpotensi besar terjadi komplikasi kehamilan dibandingkan wanita yang hamil saat berusia dibawah 35 tahun. Hasil penelitian Chiechi et al meyatakan bahwa wanita hamil berusia 35 tahun ke atas berada pada risiko yang lebih tinggi komplikasi neonatal dibandingkan kehamilan pada wanita usia 20 hingga 29 tahun.

Tabel 2. Faktor-faktor yang berhubungan dengan penggunaan kontrasepsi tradisional

\begin{tabular}{|c|c|c|c|c|c|c|c|c|}
\hline \multirow{3}{*}{ Variabel } & \multicolumn{4}{|c|}{ Penggunaan Kontrasepsi Tradisional } & \multirow{2}{*}{\multicolumn{2}{|c|}{ Jumlah }} & \multirow{3}{*}{$\begin{array}{c}\text { P- } \\
\text { value }\end{array}$} & \multirow{3}{*}{ OR } \\
\hline & \multicolumn{2}{|c|}{ Ya } & \multicolumn{2}{|c|}{ Tidak } & & & & \\
\hline & $\mathbf{n}$ & $\%$ & $\mathbf{n}$ & $\%$ & $\mathbf{n}$ & $\%$ & & \\
\hline \multicolumn{9}{|l|}{ Jumlah anak masih hidup } \\
\hline$\leq 2$ & 55 & 2,6 & 1.583 & 78,4 & 1.638 & 78,4 & 0,795 & 1,082 \\
\hline$>2$ & 14 & 0,7 & 436 & 21,6 & 450 & 21,6 & & \\
\hline \multicolumn{9}{|l|}{ Usia } \\
\hline$\leq 35$ & 32 & 1,5 & 883 & 42,3 & 915 & 43,8 & 0,664 & 1,113 \\
\hline$>35$ & 37 & 1,8 & 1.136 & 54,4 & 1.173 & 56,2 & & \\
\hline \multicolumn{9}{|l|}{ Pendidikan } \\
\hline Rendah & 26 & 1,2 & 1.280 & 61,3 & 1.306 & 62,5 & 0.000 & 0,349 \\
\hline Tinggi & 43 & 2,1 & 739 & 35,4 & 782 & 37,5 & & \\
\hline \multicolumn{9}{|l|}{ Pekerjaan } \\
\hline Bekerja & 33 & 1,6 & 1.010 & 48,4 & 1.043 & 50 & 0,719 & 0,916 \\
\hline Tidak bekerja & 35 & 1,7 & 1.009 & 48,3 & 1.045 & 50 & & \\
\hline \multicolumn{9}{|l|}{ Tempat tinggal } \\
\hline Perkotaan & 48 & 2,3 & 1.014 & 48,6 & 1.062 & 50,9 & 0,002 & 2,265 \\
\hline Perdesaan & 21 & 1 & 1.005 & 48,1 & 1.026 & 49,1 & & \\
\hline \multicolumn{9}{|l|}{ Pemanfaatan media } \\
\hline Memanfaatkan & 35 & 1,7 & 1.107 & 53 & 1.142 & 54,7 & 0,501 & 0,848 \\
\hline Tidak memanfaatkan & 34 & 1,6 & 912 & 43,7 & 946 & 45,3 & & \\
\hline Total & 69 & $\mathbf{3 , 3}$ & 2.019 & 96,7 & 2.088 & 100 & & \\
\hline
\end{tabular}


Komplikasi yang umum terjadi diantaranya yaitu bayi lahir mati, bayi lahir dengan berat badan kurang, kelahiran prematur, preeklamsia dan kematian ibu. Risiko ini meningkat seiring bertambahnya usia janin ${ }^{23}$. Besarnya risiko yang harus dihadapi wanita hamil berusia di atas 35 tahun baik pada kelahiran pertama maupun kelahiran selanjutnya menjadi dasar saran ideal untuk pengakhiran kehamilan.

Berdasarkan tabel 2 di atas, dapat diketahui bahwa tidak terdapat hubungan antara usia dengan penggunaan kontrasepsi tradisional. Wanita usia subur beserta pasangannya dalam menentukan pilihan kontrasepsi tidak mempertimbangan usia saat ini, usia ideal hamil dan melahirkan maupun usia menghentikan kehamilan. Hasil ini sesuai dengan penelitian Wijayanti yang menyebutkan tidak ada hubungan antara usia istri dengan penggunaan kontrasepsi ${ }^{15}$. Hasil ini berbeda dengan penelitian Zgliczynska, et al. dalam penelitian tersebut diperoleh hasil bahwa pemilihan kontrasepsi jangka pendek dan jangka panjang dipengaruhi oleh usia. Artinya usia berpengaruh pada pemilihan kontrasepsi ${ }^{22}$. Penelitian lainnya membuktikan bahwa variabel usia dan penolong persalinan dari tenaga kesehatan mempengaruhi pemilihan metode $\mathrm{KB}$ wanita usia reproduksi di Indonesia ${ }^{16}$. Begitu pula penelitian di Jordan yang melaporkan bahwa usia berhubungan positif dengan penggunaan kontrasepsi ${ }^{21}$. Hasil penelitian di Malawi juga menunjukkan bahwa determinan utama penggunaan kontrasepsi adalah usia ${ }^{22}$.

Tingkat pendidikan dalam penelitian ini berarti pendidikan formal yang pernah diikuti responden meskipun tidak lulus atau hanya satu hari saja masuk pada salah satu tingkat pendidikan. Pendidikan responden dikategorikan menjadi dua. Pertama pendidikan rendah, kategori ini diperuntukkan bagi responden yang tidak pernah sekolah, SD dan SLTP. Kedua pendidikan tinggi diberikan kepada responden yang pernah menduduki tingkat SLTA sampai perguruan tinggi. Sebagian besar responden berpendidikan rendah $(62,5 \%)$, hanya $37,5 \%$ responden berpendidikan tinggi. Pendidikan mempengaruhi pola pikir dan perilaku seseorang, termasuk dalam penggunaan kontrasepsi. Wanita usia subur beserta pasangannya akan menentukan pilihan penggunaan kontrasepsi berdasarkan pengetahuan yang didapatkan melalui pendidikan. Mereka mampu mengetahui kekurangan serta kelebihan masing-masing alat/metode kontrasepsi.

Responden yang berpendidikan tinggi lebih banyak yang menggunakan metode kontrasepsi tradisional. Semakin tinggi pendidikan wanita usia subur semakin tinggi menggunakan metode kontrasepsi tradisional. Hasil ini berkebalikan dengan harapan program pemerintah di mana semakin tinggi pendidikan maka semakin rendah penggunaan kontrasepsi tradisional. Semakin tinggi pendidikan, maka diharapkan semakin banyak yang beralih menggunakan kontrasepsi modern karena memiliki akses lebih besar terhadap informasi mengenai efektifitas, bentuk, jenis serta faktor kegagalan kontrasepsi. Semua informasi tersebut telah cukup menjadi pertimbangan dalam menentukan kontrasepsi modern sebagai pilihan yang tepat. Namun pendidikan tinggi justru tidak mendorong meningkatnya pemakaian kontrasepsi modern. Hasil penelitian di India mengungkapkan bahwa salah satu faktor pendukung terbesar penggunaan kontrasepsi tradisional pada kalangan berpendidikan tinggi dan wanita yang lebih kaya karena efek samping yang sehat ${ }^{14}$. Senada dengan itu, penelitian Adefalu, et al pada tahun 2019 menyebutkan bahwa salah satu faktor penghambat pemakaian kontrasepsi adalah efek samping dan pendidikan kesehatan ${ }^{24}$.

Penelitian ini menghasilkan bahwa terdapat hubungan pendidikan dengan penggunaan kontrasepsi tradisional. Nilai OR (odds ratio) menunjukkan bahwa responden dengan pendidikan tinggi memiliki kemungkinan menggunakan metode kontrasepsi tradisional sebanyak 0,349 kali lebih besar dibandingkan dengan wanita yang berpendidikan rendah. Hasil ini sesuai dengan penelitian terdahulu yang membuktikan bahwa status pendidikan secara signifikan berkaitan dengan penggunaan kontrasepsi tradisional $^{25}$. Sejalan dengan itu, penelitian lain menjelaskan bahwa tingkat pendidikan mempengaruhi penggunan kontrasepsi. Hasil penelitian Setiasih, Widjanarko \& Istiarti menunjukkan ada hubungan antara pengetahuan dengan pemilihan metode kontrasepsi ${ }^{26}$. Arbab et al meneliti wanita usia subur di Qatar dalam partisipasinya menggunakan kontrasepsi dipengaruhi oleh pengetahuan, di mana pengetahuan tentang keluarga berencana akan meningkat seiring dengan tingginya tingkat pendidikan. Zgliczynska, et al, menyatakan bahwa pendidikan sebagai salah satu faktor yang terkait dengan penggunaan kontrasepsi hormonal atau non-hormonal ${ }^{22}$.

Sebanyak $50 \%$ responden adalah wanita bekerja. Wanita yang tidak bekerja lebih banyak yang menggunakan metode kontrasepsi tradisional dibandingkan dengan mereka yang bekerja. Hal ini berarti wanita usia subur yang menggunakan metode kontrasepsi tradisional merupakan wanita yang tidak disibukkan dengan aktifitas menghasilkan penghasilan. Mereka merupakan ibu rumah tangga yang fokus mengurus rumah tangga dan pengasuhan anak. Waktu yang dihabiskan lebih banyak di rumah sehingga kondisi ini berpotensi lebih besar untuk melakukan hubungan intim suami istri dan memiliki anak dibandingkan dengan wanita bekerja. Metode kontrasepsi modern lebih tepat dipilih dibandingkan metode tradisional yang dapat menyebabkan kegagalan KB.

Tidak terdapat hubungan antara pekerjaan dengan penggunaan kontrasepsi tradisional ( $\mathrm{p}$ value $=0,719$ ), yang berarti para wanita usia subur memilih metode kontrasepsi tradisional bukan dilatarbelakangi faktor bekerja maupun 
tidak bekerja. Penelitian di Nepal menyebutkan bahwa tidak ada hubungan antara wanita yang bekerja dan penggunaan kontrasepsi ${ }^{27}$. Hasil penelitian di Malawi justru menemukan determinan utama penggunaan kontrasepsi adalah status pekerjaan $^{18}$. Salah satu faktor positif yang mempengaruhi penggunaan kontrasepsi pada wanita di Afrika adalah pekerjaan $^{28}$. Wanita usia 18-24 tahun di Amerika Serikat dengan kesulitan keuangan yang tinggi cenderung tidak menggunakan kontrasepsi jangka panjang, bahkan cenderung tidak menggunakan kontrasepsi ${ }^{29}$.

Sebanyak 50,9\% responden tinggal di wilayah perkotaan. Masyarakat yang tinggal pada wilayah perkotaan tentunya akan berbeda dengan mereka yang tinggal di pedesaan, terutama terkait akses informasi mengenai kontrasepsi, tenaga pelayanan, fasilitas pelayanan, konsultasi kesehatan dan lain-lain. Masyarakat perkotaan lebih mudah mengakses seluruh fasilitas tersebut. Lain halnya dengan masyarakat pedesaan yang minim akan fasilitas tersebut. Penelitian Lasong et al pada tahun 2019 di Zambia Afrika Timur menjelaskan bahwa wanita pedesaan memiliki akses terbatas ke layanan kesehatan, termasuk keluarga berencana, dibandingkan dengan wanita penduduk perkotaan $^{30}$. Kurangnya informasi tentang komplikasi kehamilan di pedesaan menjadikan disparitas dalam penggunaan layanan kesehatan reproduksi di semua negara $^{31}$. Keterbatasan ini harus disiasati agar tidak memicu penurunan penggunaan kontrasepsi yang berdampak pada penambahan kehamilan. Meskipun demikian, penelitian ini memperoleh hasil bahwa wanita usia subur yang tinggal di perkotaan justru lebih memilih menggunakan metode tradisional, padahal mereka memiliki akses yang mudah terhadap alat dan cara kontrasepsi modern.

Tabel 2 menunjukkan adanya hubungan tempat tinggal dengan penggunaan kontrasepsi tradisional ( $\mathrm{p}$ value = 0,002). Nilai OR (odds ratio) membuktikan bahwa responden yang bertempat tinggal di perkotaan akan berkemungkinan menggunakan metode kontrasepsi tradisional sebanyak 2,265 kali lebih besar dibandingkan dengan wanita yang tinggal di pedesaan. Hal ini sesuai dengan penelitian di Bangladesh yang dilakukan oleh Ahmed pada tahun 2016. Penelitian tersebut menunjukkan bahwa wilayah tempat tinggal mempunyai hubungan yang signifikan dalam penggunaan kontrasepsi sekalipun persentasenya tidak menunjukkan adanya perbedaan yang besar antara tinggal di perkotaan dan pedesaan ${ }^{32}$. Penelitian di Nigeria dan Zambia juga menunjukan hasil yang sama, yaitu bahwa wilayah tempat tinggal merupakan salah satu prediktor signifikan penggunaan kontrasepsi ${ }^{33}$. Penelitian Agbadi et al., menyebut salah satu faktor sosio demografi berkorelasi positif pada penggunaan kontrasepsi, yaitu tempat tinggal perkotaan ${ }^{34}$. Hasil penelitian Haile menunjukkan bahwa wilayah tempat tinggal responden secara signifikan merupakan faktor-faktor yang menentukan penggunaan kontrasepsi meskipun konteksnya kontrasepsi jangka panjang ${ }^{35}$.

Pemanfaatan media adalah bentuk pemanfaatan sumber informasi yang berkaitan tentang KB dalam bentuk pernah diakses/diperoleh dengan melihat, membaca maupun mendengar dari salah satu sumber informasi dalam 6 bulan terakhir. Sumber informasi yang dimaksud bisa dari radio, televisi, internet, pamflet, brosur, koran, majalah, spanduk, baliho, mural, banner, mobil unit pelayanan $\mathrm{KB}$, web site BKKBN, instagram BKKBN. Jumlah responden yang memanfaatkan media informasi KB masih tergolong rendah, hanya $54,7 \%$ saja. Responden memanfaatkan media untuk mencari informasi terkait keluarga berencana. Informasi diakses berupa jenis alat kontrasepsi, bentuk alat kontrasepsi, tingkat efektifitas alat kontrasepsi, dan masa penggunaan alat kontrasepsi. Hal ini berarti para responden merupakan wanita usia subur yang aktif mencari informasi dari media dan melek akan informasi.

Para pengguna kontarsepsi tradisional merupakan wanita usia subur yang aktif mencari informasi pada media dan memiliki pemahaman tentang keluarga berencana. Salah satu upaya yang dilakukan untuk mendorong para wanita usia subur beralih pada kontarsepsi modern adalah dengan lebih banyak informasi tentang sumber metode yang tersedia bagi mereka. Bentuk intervensi keluarga berencana harus berfokus pada wanita yang lebih muda dan berparitas tinggi karena mereka lebih cenderung menggunakan metode tradisional ${ }^{36}$. Sumber informasi berupa media dirasakan kurang menarik wanita usia subur untuk beralih menggunakan kontrasepsi modern. Menurut penelitian Zgliczynska, et al, salah satu sumber informasi yang dapat dipercaya adalah dokter, bersama mencari informasi dengan suami atau pasangan. Dokter dianggap sebagai sumber informasi yang dapat dan paling dipercaya dan akurat. Suami atau pasangan membantu wanita mengambil keputusan yang tepat tentang pilihan kontrasepsi dengan efektifitas tinggi ${ }^{22}$.

Tidak terdapat hubungan pemanfaatan media dengan penggunaan kontrasepsi tradisional ( $\mathrm{p}$ value $=$ 0,501). Berbeda dengan hasil penelitian Zgliczynska, et al salah satu faktor yang terkait dengan penggunaan kontrasepsi hormonal atau non-hormonal adalah sumber informasi tentang kontrasepsi ${ }^{22}$. Begitu pula penelitian Bakibinga, et al yang menunjukkan adanya korelasi signifikan dari penggunaan kontrasepsi wanita dengan akses informasi perencanaan kehamilan melalui radio ${ }^{37}$. Hasil penelitian Ntoimo, et, al., menyebutkan bahwa salah satu faktor prediktor yang signifikan dalam penggunaan kontrasepsi pada pasangan di Nigeria dan Zambia adalah frekuensi mendengarkan informasi kesehatan reproduksi melalui radio $^{33}$. Penelitian terdahulu juga melaporkan bahwa wanita yang mendengar informasi mengenai $\mathrm{KB}$ di radio berkorelasi positif atau lebih mungkin untuk menggunaan 
kontrasepsi daripada mereka yang tidak mengakses informasi melalui radio $^{38}$.

\section{SIMPULAN}

Faktor yang berhubungan dengan penggunaan metode kontrasepsi tradisional adalah faktor pendidikan dan tempat tinggal. Faktor jumlah anak masih hidup, usia, pekerjaan dan pemanfaatan media tidak berpengaruh pada penggunaan kontrasepsi tradisional. Wanita usia subur yang berpendidikan tinggi dan tinggal di kota justru lebih memilih menggunakan kontrasepsi tradisional. Pemerintah melalui BKKBN perlu lebih gencar dalam melakukan KIE tentang keuntungan metode kotrasepsi modern melalui media cetak maupun elektronik. Penyampaian informasi dapat melibatkan tokoh masyarakat berpendidikan tinggi, agar menjadi contoh bagi mereka yang berpendidikan tinggi dan tinggal di perkotaan untuk menggunakan metode kontrasepsi modern dibandingkan tradisional.

\section{KEPUSTAKAAN}

1. Lembaga Demografi Fakultas Ekonomi Univeristas Indonesia. Dasar-Dasar Demografi. Jakarta, Id: Salemba Empat. 2013.

2. Badan Kependudukan Dan Keluarga Berencana Nasional. Panduan Pewawancara Kuesioner Rumah Tangga, Jakarta: BKKBN. 2019.

3. Badan Kependudukan Dan Keluarga Berencana Nasional. Pedoman Penggarapan Peningkatan Partisipasi Pria Dalam Program Keluarga Berencana Dan Kesehatan Reproduksi Yang Berwawasan Gender, Jakarta: BKKBN. 2001.

4. Bradley, S., Polis, C. B., Bankole, A., \& Croft, T. Global Contraceptive Failure Rates: Who Is Most At Risk?. Studies In Family Planning, 50(1), 3-24. 2019. Https://Doi.Org/10.1111/Sifp.12085

5. Badan Kependudukan Dan Keluarga Berencana Nasional. Faktor-Faktor Yang Mempengaruhi Penggunaan Metode Kontrasepsi Jangka Panjang Di Enam Wilayah Indonesia. Jakarta: BKKBN. 2011.

6. Chotimah, Khusnul Dan Fitriana Putri Utami Faktor Pemungkin Penggunaan Kontrasepsi Tradisional Di Kota Yogyakarta, 1-13. 2019.

7. Ajayi, A. I., Adeniyi, O. V., \& Akpan, W. Use Of Traditional And Modern Contraceptives Among Childbearing Women: Findings From A Mixed Methods Study In Two Southwestern Nigerian States. Bmc Public Health, 18(1), 1-9. 2018. Https://Doi.Org/10.1186/S12889-018-5522-6

8. Lubis, Istichomah Dan Monika. Gambaran Faktor Yang Mempengaruhi Pemilhan Kontrasepsi Tradisional Di Kelurahan Guwonsari Kecamatan Pajangan Bantul. Jurnal Keperawatan. 2019. Doi: 10.29238
9. Nurmayanti, D. R., Ramie, A., \& Herawati. Kepercayaan Akseptor Keluarga Berencana Wanita Dengan Pemilihan Metode Kontrasepsi Di Desa Lok Besar Wilayah Kerja Puskesmas Birayang Kabupaten Hulu Sungai Tengah. Dunia Keperawatan, Vol 5, No 2. 2017

10. Bertand. Audience Reasearch For Improving Family Planning Communication Program. The Community And Family Study Centre. Chicago. 1980. Diunduh $\begin{array}{llll}\text { Pada } & 1 & \text { Agustus } & 2016 \quad \text { Dari }\end{array}$ Http://Pdf.Usaid.Gov/Pdf_Docs/Pnaak992.Pdf

11. Bulatao, R.A. Toward A Framework For Understanding Contraseptive Method Choice Choosing A Contraceptive : Method Choice In Asia And The United States. Westview, Boulder. 1989.

12. Ram, F., Shekhar, C., \& Chowdhury, B. Use Of Traditional Contraceptive Methods In India \& Its Sociodemographic Determinants. Indian Journal Of Medical Research, 140(November), 17-28. 2014.

13. Titaley C.R., Sallatalohi N. Utilization Of Family Planning Contraceptives Among Women In The Coastal Area Of South Buru District, Maluku, 2017. Kesmas: National Public Health Journal. , P-Issn: 1907-7505, E-Issn: 2460-06012020; 15(1): 40-47. 2020. Doi:10.21109/Kesmas.V15i1.2542.

14. Lontaan, A., Kusmiyati, K., \& Dompas, R. Faktor Yang Berhubungan Dengan Pemilihan Kontrasepsi Pasangan Usia Subur Di Puskesmas Damau Kabupaten Talaud. Jurnal Ilmiah Bidan, 2(1), 91154. 2014.

15. Wijayanti, Urip Tri. Determinan Penggunaan Kontrasepsi (Suatu Analisis Hasil Sdki Tahun 2017 Provinsi Jawa Tengah). Jurnal Inovasi. 2020.

16. Hartono, R. K. Determinan Pemilihan Kb Pada Wanita Usia Reproduksi Di Indonesia (Analisis Data Susenas 2012). Journal Of Nursing And Health, 1(1), 17-26. 2019. Https://Doi.Org/10.25099/Jnh.Vol1.Iss1.13

17. O'hara, K., Tsai, L. C., Carlson, C. E., \& Haidar, Y. M. Experiences Of Intimate-Partner Violence And Contraception Use Among Ever-Married Women In Jordan. Eastern Mediterranean Health Journal = La Revue De Sante De La Mediterranee Orientale = AlMajallah Al-Sihhiyah Li-Sharq Al-Mutawassit, 19(10), 876-882. 2013.

18. Palamuleni M. E. Socio-Economic And Demographic Factors Affecting Contraceptive Use In Malawi. African Journal Of Reproductive Health, 17(3), 91-104. 2013.

19. Chiechi, L. M., Fanelli, M., Lobascio, A., Serio, G., \& Loizzi, P. La Gravidanza Nelle Ultratrentacinquenni. Quale Rischio? [Pregnancy In Women Over 35 Years Of Age. What Risk?]. Minerva Ginecologica, 48(10), 391-396. 1996. 
20. Obwoya J. G., Wulifan J. K., Kalolo A. Factors Influencing Contraceptives Use Among Women In The Juba City Of South Sudan. Hindawi International Journal Of Population Research Volume 2018, Article Id 6381842, 7 Pages. 2018. Doi.10.1155/2018/6381842

21. Hossain Mb., Khan Mhr., Ababneh F., Shaw Jeh. Identifying Factors In Fluencing Contraceptive Use In Bangladesh: Evidence From Bdhs 2014 Data. Bmc Public Health. 18:192. 2018. Doi10.1186/S12889-0185098-1

22. Zgliczynska, M., Szymusik, I., Sierocinska, A., Bajaka, A., Rowniak, M., Sochacki-Wojcicka, N., Wielgos, M., \& Kosinska-Kaczynska, K. Contraceptive Behaviors In Polish Women Aged 18-35-A Cross-Sectional Study. International Journal Of Environmental Research And Public Health, 16(15), 2723. 2019. Https://Doi.Org/10.3390/Ijerph16152723

23. Heazell, A. E. P., Newman, L., Lean, S. C., \& Jones, R. L. Pregnancy Outcome In Mothers Over The Age Of 35. Current Opinion In Obstetrics And Gynecology, 30(6), 337-343. 2018 Https://Doi.Org/10.1097/Gco.0000000000000494

24. Adefalu, A. A., Ladipo, O. A., Akinyemi, O. O., Popoola, O. A., Latunji, O. O., \& Iyanda, O. Qualitative Exploration Of Factors Affecting Uptake And Demand For Contraception And Other Family Planning Services In North-West Nigeria. African Journal Of Reproductive Health, 23(4), 63-74. 2019. Https://Doi.Org/10.29063/Ajrh2019/V23i4.8

25. Rabiu, A., \& Rufa'i, A. A. The Role Of Traditional Contraceptive Methods In Family Planning Among Women Attending Primary Health Care Centers In Kano. Annals Of African Medicine, 17(4), 189-195. 2018. Https://Doi.Org/10.4103/Aam.Aam_60_17)

26. Setiasih, S., Widjanarko, B., \& Istiarti, T. Analisis Faktor-Faktor Yang Mempengaruhi Pemilihan Metode Kontrasepsi Jangka Panjang (Mkip) Pada Wanita Pasangan Usia Subur (Pus) Di Kabupaten Kendal Tahun 2013. Jurnal Promosi Kesehatan Indonesia, 11(2), 32-46. 2016. Https://Doi.Org/10.14710/Jpki.11.2.32-46

27. Satyavada, A., \& Adamchak, D. J. Determinants Of Current Use Of Contraception And Children Ever Born In Nepal. Social Biology, 47(1-2), 51-60. 2000. Https://Doi.Org/10.1080/19485565.2000.9989009

28. Blackstone, S. R., Nwaozuru, U., \& Iwelunmor, J. Factors Influencing Contraceptive Use In Sub-Saharan Africa: A Systematic Review. International Quarterly Of Community Health Education, 37(2), 79-91. 2017. Https://Doi.Org/10.1177/0272684x16685254

29. Lyons, S., Arcara, J., Deardorff, J., \& Gomez, A. M. Financial Strain And Contraceptive Use Among Women In The United States: Differential Effects By
Age. Women's Health Issues : Official Publication Of The Jacobs Institute Of Women's Health, 29(2), 153160.

2019.

Https://Doi.Org/10.1016/J.Whi.2018.12.006

30. Lasong J., Zhang Y., Gebremedhin S. A., Opoku S., Abaidoo C. S., Et Al. Determinants Of Modern Contraceptive Use Among Married Women Of Reproductive Age: A Cross- Sectional Study In Rural Zambia. 2019. Doi:10.1136/Bmjopen-2019-030980.

31. Ogundele, O. J., Pavlova, M., \& Groot, W. Inequalities In Reproductive Health Care Use In Five West-African Countries: A Decomposition Analysis Of The WealthBased Gaps. International Journal for Equity In Health, 19(1), 44. Https://Doi.Org/10.1186/S12939-020-01167-7

32. Ahmed Z.I, Nazrul I.M P, Laily Khatun, Mosiur R Et Al. Prevalence And Determinants Of Contraceptive Use Among Employed And Unemployed Women In Bangladesh. International Journal Of Mch And Aids, Volume 5, Issue 2, 92-102. 2016. Issn 2161-864x. Doi: 10.21106/Ijma.83.

33. Ntoimo, L., \& Chirwa-Banda, P. Examining The Role Of Couples' Characteristics In Contraceptive Use In Nigeria And Zambia. African Journal Of Reproductive Health, 21(4), 93-101. 2017. Https://Doi.Org/10.29063/Ajrh2017/V21i4.10

34. Agbadi, P., Eunice, T. T., Akosua, A. F., \& Owusu, S. Complex Samples Logistic Regression Analysis Of Predictors of The Current Use Of Modern Contraceptive Among Married Or In-Union Women In Sierra Leone: Insight From The 2013 Demographic And Health Survey. Plos One, Vol 15, No 4. 2020. Https://Doi.Org/10.1371/Journal.Pone.0231630

35. Haile, B. T., \& Tsehay, Y. E. Disparities In LongActing Reversible Contraceptive Utilization Among Married Women In Ethiopia: Findings Of The Ethiopian Demographic And Health Survey. International Journal Of Reproductive Medicine, 2020, 3430975. Https://Doi.Org/10.1155/2020/3430975

36. Almalik, M., Mosleh, S., \& Almasarweh, I. Are Users Of Modern And Traditional Contraceptive Methods In Jordan Different?. Eastern Mediterranean Health Journal $=$ La Revue De Sante De La Mediterranee Orientale $=$ Al-Majallah Al-Sihhiyah Li-Sharq AlMutawassit, 24(4), 377-384. 2018. Https://Doi.Org/10.26719/2018.24.4.377

37. Bakibinga, P., Matanda, D. J., Ayiko, R., Rujumba, J., Muiruri, C., Amendah, D., \& Atela, M. Pregnancy History And Current Use Of Contraception Among Women Of Reproductive Age In Burundi, Kenya, Rwanda, Tanzania And Uganda: Analysis Of Demographic And Health Survey Data. Bmj 
Open, 6(3),

E009991.

2016.

Https://Doi.Org/10.1136/Bmjopen-2015-009991

38. Arbab, A.A., Bener, A. \& Abdulmalik, M. Prevalence, Awareness And Determinants Of Contraceptive Use In Qatari Women. Emhj - Eastern Mediterranean Health Journal, 17 (1), 11-18, 2011. Issn 1020-3397 